\title{
An Empirical test of Economic Growth, Industrial Structure and the Urban-Rural Income Gap \\ - based on the data of 1978-2014 years in Tibet
}

\author{
Duzhu Rob ${ }^{1, \text { a }}$ \\ ${ }^{1}$ Agricultural and Animal Husbandry College of Tibet, NyingChi in Tibet,860000 \\ ${ }^{\mathrm{a}}$ email,
}

Keywords: Economic Growth; Industrial Structure; Income Gap between Urban And Rural Areas; Tibet

\begin{abstract}
Using the VAR model to 1978-2014 in Tibet economy growth, industrial structure and urban and rural residents income gap of cointegration test, impulse response function and variance decomposition analysis, the long-term cointegration relationship exists between that economic growth, industrial structure and the income gap between urban and rural residents, the initial income gap between urban and rural residents and economic growth has the curing effect on the income of urban and rural residents, industrial structure can improve the income gap, but in the long run, income gap between urban and rural residents and economic growth to have the improvement function to the income gap between urban and rural residents, industrial structure will increase income gap, and the industrial structure of the income gap between urban and rural residents with significantly the rate of.
\end{abstract}

\section{Preface}

The economy of our country has been developing rapidly since the reform and opening up. But also accompanied by unbalanced regional development, excess capacity, a series of problems such as prominent structure in urban and rural. The relationship between economic growth, industrial structure and the income gap between urban and rural areas has become particularly important in the study of the relationship between the three, is conducive to the new situation, the development of appropriate economic policies to accelerate the development of less developed areas of the economy and to achieve a comprehensive well-off society.

\section{Model Constructing}

Econometric Model. Vector auto-regressive model. Vector auto-regression model (VaR) model is used to predict the interrelated time series system and analysis of random disturbance on the system variables of dynamic impact, thus explaining various economic shocks on economic variables forming effect (Tiemei Gao, 2009). Based on the study of the relationship between economic growth, industrial structure and the income difference between urban and rural residents, the paper selects the time series of 1978-2014 years, so the following VAR model can be established:

$$
Y_{t}=c+\sum_{t=1}^{k} \alpha_{i} Y_{t-1}+\varepsilon_{t}
$$

In the formula, is the vector of the economic growth (LnGNP), the industrial structure (LnIND) and the income gap between urban and rural residents (LnIGAP); for the lag period; for the regression coefficient; for the disturbance vector. The measurement software used in this paper is EViews6.0.

Determination of lag period. By using the Lag Length Criteria, repeated test, finally obtains the lag period is 1 order, the result is shown in table 1. 
Table 1 the lag phase of VAR model

\begin{tabular}{|c|c|c|c|c|c|c|}
\hline \multirow[b]{2}{*}{ Lag } & \multicolumn{6}{|c|}{ 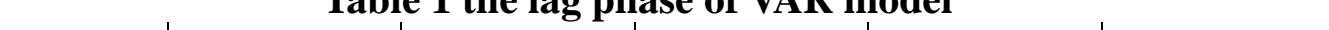 } \\
\hline & LogL & LR & FPE & AIC & $\mathrm{SC}$ & HQ \\
\hline 0 & $1^{-43.312}$ & NA & 0.002831 & 2.646412 & 2.779728 & 2.692433 \\
\hline & 124.31 & 296.9307 & $3.29 \mathrm{e}-07$ & -6.417713 & -5.884451 & -6.233631 \\
\hline & & ( & ( & ( & & ( \\
\hline & $99^{130.00}$ & 9.115033 & $4.02 \mathrm{e}-07$ & -6.228964 & -5.295756 & -5.906821 \\
\hline
\end{tabular}

Note: * indicates the selected lag order.

Variable Selection. 1, economic growth: usually refers to a country or region in a certain period of time per capita output or per capita income continued to increase, based on this, select the per capita GDP to indicate economic growth.

2, the industrial structure: according to the classification of three industries, and petty - Clark theorem, the industrial structure is from the first industry to the second and tertiary industries evolution. Therefore, select the third industry output value to indicate the change of industrial structure.

3 , the income gap between urban and rural residents, income gap is the comparison of urban and rural residents' income, namely urban residents per capita disposable income of farmers and herdsmen per capita net income ratio, the value is, the greater the income gap between urban and rural residents.

\section{Empirical testing and analyzing}

Unit Root Testing. Before the time series regression, the need for the sequence of the stability test. In this paper, the stability of the time series of unit root test is used to test the time series, and the results are shown in table 2 . The result is that the sequence is I (0) sequence, that is, all the variables are in the order of 0 .

Table 2 unit root testing results

\begin{tabular}{|c|c|c|c|c|c|}
\hline variable & t-Statistic & level1\% & level5\% & level10\% & Prob.* \\
\hline${ }_{\mathrm{P}}$ LnIGA & -5.4023 & -3.6999 & -2.9763 & -2.6274 & 0.0001 \\
\hline LnGNP & -5.9023 & -3.6329 & -2.9484 & -2.6129 & 0.0000 \\
\hline LnIND & -5.8475 & -3.6394 & -2.9511 & -2.6143 & 0.0000 \\
\hline
\end{tabular}

Co-Integration Test. Cointegration test is to test whether there is a long-term dynamic equilibrium relationship between variables, the test method is based on the Johansen co integration test based on regression coefficient and regression residuals based cointegration test two. Here the main use of Johansen co integration test, the results are shown in table 3.

\begin{tabular}{l|c|c|c|c}
\multicolumn{2}{c}{ Table 3 results of co-integration test } \\
$\begin{array}{c}\text { Original } \\
\text { hypothesis }\end{array}$ & $\begin{array}{c}\text { Maximum } \\
\text { eigenvalue }\end{array}$ & Trace statistic & $\begin{array}{c}0.05 \% \quad \text { critical } \\
\text { value }\end{array}$ & \multirow{2}{*}{ Prob.** } \\
\hline None $*$ & 0.5655 & 48.6116 & 29.7971 & 0.0001 \\
\hline At most 1 & 0.4772 & 21.9353 & 15.4947 & 0.0047 \\
\hline At most 2 & 0.0363 & 1.1817 & 3.8415 & 0.2770
\end{tabular}

Cointegration test results show that economic growth, industrial structure and urban and rural residents in the income gap between the existence of at least 1 co integration relationship.Regression model was carried out, and the results were shown in table 4 . The results show that the gap between urban and rural residents in the 1 period will widen the income gap, and the 1 phase of economic growth will narrow the income gap between urban and rural residents. But the lag phase 1 industrial structure will expand the income gap between urban and rural areas, that in the long run, the income gap between urban and rural residents and economic growth, industrial 
structure for every $1 \%$ increase in the and the were caused by urban and rural residents, the income gap between $0.9456 \%,-0.2589 \%, 0.2162 \%$; At the same time, the income gap between urban and rural areas in the lag period of 1 has a promoting effect on economic growth, and the promotion effect is $0.0684 \%$, Lag 1 period of economic growth has a more significant role of self promotion, the effect is $1.041 \%$, but the industrial structure of the 1 lag period will inhibit economic growth; In addition, the income gap between urban and rural residents, the economic growth and the industrial structure of the 1 phase of the lag period can promote the industrial structure, which is $0.0735 \%$, $0.2662 \%$ and $0.7667 \%$, respectively.

Table 4 estimation of vector autoregressive model

\begin{tabular}{l|c|c|c} 
& LnIGAP & LnGNP & LnIND \\
\hline LnIGAP(-1) & 0.9456 & 0.0684 & 0.0735 \\
\hline & $(0.0683)$ & $(0.0508)$ & $(0.0964)$ \\
\hline LnGNP(-1) & {$[13.8501]$} & {$[1.3463]$} & {$[0.7623]$} \\
\hline & -0.2589 & 1.0410 & 0.2662 \\
\hline LnIND(-1) & $(0.1273)$ & $(0.0947)$ & $(0.1797)$ \\
\hline & {$[-2.0345]$} & {$[10.9926]$} & {$[1.4810]$} \\
\hline & 0.2162 & -0.0356 & 0.7667 \\
\hline C & $(0.1059)$ & $(0.0788)$ & $(0.1496)$ \\
\hline & {$[2.0413]$} & {$[-0.4517]$} & {$[5.1260]$} \\
\hline R-squared & 0.4425 & -0.0018 & -0.2804 \\
\hline Adj. R-squared & $(0.1983)$ & $(0.1475)$ & $(0.2800)$ \\
\hline Sum sq. resids & {$[2.2322]$} & {$[-0.0122]$} & {$[-1.0015]$} \\
\hline S.E. equation & 0.9054 & 0.9980 & 0.9947 \\
\hline F-statistic & 0.8966 & 0.9977 & 0.9942 \\
\hline Log likelihood & 0.2930 & 0.1622 & 0.5843 \\
\hline Akaike AIC & 0.0957 & 0.0712 & 0.1351 \\
\hline Schwarz SC & 102.1441 & 5099.6400 & 1995.1580 \\
\hline Mean dependent & 35.5196 & 46.1596 & 23.0925 \\
\hline S.D. dependent & -1.7511 & -2.3422 & -1.0607 \\
\hline () the vale of & -1.5751 & -2.1663 & -0.8847 \\
\hline & 1.2125 & 4.3062 & 3.4048 \\
\hline & 0.2975 & 1.4902 & 1.7719
\end{tabular}

Note: ( ) the value of statistical error, the value for the t- statistics [].

Impulse Response and Variance Decomposition. Co integration test is only to examine the long-term relationship between variables, but can not reflect the dynamic characteristics and contribution of a variable to another variable. Therefore, we can use the impulse response and variance decomposition to analyze the interaction between variables.

The impulse response. The impulse response function model of economic growth, industrial structure and urban and rural residents' income gap is established by using the orthogonal impulse response function, and the results are shown in Figure1.

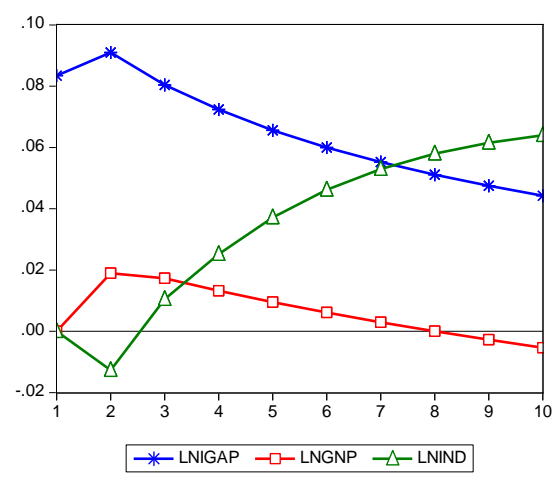

Figure 1 Cholesky decomposition of the income gap between urban and rural residents 
(1) The impact response of the income gap between urban and rural residents on their own. In the early stage, the income gap between urban and rural residents was strengthened, and the income of urban and rural residents was weakened after the second period. That is, the gap between urban and rural residents' income will continue to shrink over time, and will not strengthen the gap between urban and rural residents' income over time.

(2) The impact of economic growth on the income gap between urban and rural residents. Initial economic growth has a positive effect on the income of urban and rural residents, and the maximum effect is achieved in the second phase. As the economy continues to grow, the income of urban and rural residents has been decreasing, and in the eighth phase to the negative effect.

(3) The impact of industrial structure on the income gap between urban and rural residents. The initial industrial structure has a negative effect on the income of urban and rural residents, and at the second stage to achieve the minimum effect, and then turned to the top, in the third period of urban and rural residents' income has a positive effect.

Variance decomposition. When variance decomposition is decomposed, the contribution of each structure impact to the endogenous variables in VAR model is investigated, and the variance is expressed in the form of variance. LnIGAP variance decomposition of urban and rural residents' income gap, and the results are shown in table 5 . As can be seen from table 5 , the contribution rate of urban and rural residents showed a decreasing trend; The contribution rate of economic growth to the income gap between urban and rural residents reached $0.2594 \%$, and then decreased; The contribution rate of the industrial structure to the urban and rural residents' income gap is increasing, the contribution rate of the 34 phase is the largest, and the contribution rate is $47.4707 \%$.

\begin{tabular}{c|c|c|c|c}
\multicolumn{5}{c|}{ Table 5 Variance Decomposition of LnIGAP } \\
nce & S.E. & LnIGAP & LnGNP & LnIND \\
\hline 1 & 0.0957 & 100.0000 & 0.0000 & 0.0000 \\
\hline 2 & 0.1336 & 97.5832 & 0.0327 & 2.3841 \\
\hline 3 & 0.1630 & 93.3875 & 0.0843 & 6.5283 \\
\hline 4 & 0.1885 & 88.5693 & 0.1370 & 11.2938 \\
\hline 5 & 0.2112 & 83.7986 & 0.1820 & 16.0195 \\
\hline 6 & 0.2317 & 79.3979 & 0.2162 & 20.3859 \\
\hline 7 & 0.2502 & 75.4863 & 0.2400 & 24.2741 \\
\hline 8 & 0.2669 & 72.0781 & 0.2534 & 27.6685 \\
\hline 9 & 0.2819 & 69.1395 & 0.2594 & 30.6011 \\
\hline 10 & 0.2953 & 66.6191 & 0.2593 & 33.1215
\end{tabular}

\section{Conclusion}

Through the analysis of co integration test, impulse response function and variance decomposition of VAR model, we found that there is a long-term cointegration relationship between economic growth, industrial structure and the income gap between urban and rural residents, The income gap between urban and rural residents has a curing effect in the early stage, and has its own weak mechanism for a long time, and will continue to narrow the gap over time; In the long term, the income gap between urban and rural residents, economic growth, industrial structure every $1 \%$ increase, will lead to changes in the income gap between urban and rural residents $0.9456 \%$, $-0.2589 \%, 0.2162 \%$. The effect of initial economic growth on the income of urban and rural residents. As the economy continues to grow, the effect of the income of urban and rural residents continue to decline; The initial industrial structure has a negative effect on the income of urban and rural residents, but after the third period, it has a positive effect on the income of urban and rural residents. The biggest contribution to the income gap between urban and rural areas is the industrial structure, which reached the maximum value at $34(47.4707 \%)$, and the contribution rate of economic growth is relatively small. 


\section{Reference}

[1] Xiaohui Yao, Jinqiu Liao. Income gap between urban and rural areas and economic growth: An Empirical Analysis Based on the STR model [J]. economic review, 2009 (3): 29-37.

[2] Shaoping Wang, Zhigang Ouyang. Measurement of urban rural income gap in China and its effect on economic growth [J]. economic research, 2007,42 (7): 44-55.

[3] Jianhui Zhang,Tao Jin. Transformation of economic growth and urban rural income gap: China's experience (1978-2008) [J]. academic monthly, 2011 (7): 79-87.

[4] Xianyin Li. Urbanization, economic growth and the income gap between urban and rural areas [J]. agricultural technology and economy, 2011 (8): 50-57.

[5] Xiaojing Chao, Baoping Ren. Income gap between urban and rural areas and the quality of economic growth China [J]. finance research, 2014 (5):1-9.

[6] Wanji Zheng, Azhong Ye. Upgrading of industrial structure and economic growth -- Research on VAR model based on semi parametric spatial panel [J]., 2015 (10):61-68.

[7] Yu Cao,Xiaohong Chen, Yueru Ma. Urbanization, urban and rural income gap and economic growth: An Empirical Study Based on Provincial Panel Data in China [J]. statistical research, 2010,27 (3): 29-37.

[8] Zhengbin Ma. An empirical study on the adjustment of industrial structure and the promotion of urban and rural income [J]. Journal of Xinjiang University Of Finance and Economics, 2008 (1): 27-32.

[9] Su Yan. The change of industrial structure, labor migration and income distribution -- An Empirical Study Based on VAR model [J]. Journal of finance, 2012 (1): 3-8.

[10] Xueping Shi,Lianjiu Song,Hongmei Gong,Yan He. Characteristics of income gap between urban and rural residents in Tibet and Countermeasures of farmers and herdsmen's income increase [J]. agricultural modernization research, 2012,33 (5): 589-593.

[11] Huang Ouyang. The international experience of residents' income and the coordinated growth of the national economy and the present situation of our country [J]. economic research reference, 2012 (25): 24-54.

[12] Anping Chen. The industrial distribution, spatial structure of China's economic growth and the gap between urban and rural income [J]. management review, 2013,25 (11): 23-32.

[13] Chong Lu,Yuan Liu,Peiyuan Jiang. Industrial structure, income structure of rural residents and the income gap between urban and rural areas [J]. China's population, resources and environment, 2014,24 (3):147-151.

[14] Tiemei Gao. Econometric analysis methods and modeling: EViews applications and examples (Second Edition) [M]. Tsinghua University press, 2009:267. 